\title{
Diagnostic Accuracy of Radiology and Endoscopy in the Assessment of Adenoid Hypertrophy
}

\author{
${ }^{1}$ Mohammed R Dawood, ${ }^{2}$ Ammar H Khammas
}

\begin{abstract}
Aim: To clarify the diagnostic accuracy of the lateral X-ray of nasopharynx, and the flexible nasopharyngoscopy in the assessment of adenoid hypertrophy, with the preoperative rigid nasal endoscopic observation, as it was considered as a reference standard guide.
\end{abstract}

Materials and methods: This is a prospective observational study that included 80 children who planned to undergo adenoidectomy due to the symptoms found related to adenoid hypertrophy. All the children underwent a relevant clinical history and full ear, nose, and throat (ENT) examination, and the grading of adenoid hypertrophy was done preoperatively with the lateral $\mathrm{X}$-ray of the nasopharynx and the flexible nasopharyngoscopy. These findings were analyzed and compared with the peroperative rigid nasal endoscopic assessment of adenoid hypertrophy, which was considered as a reference guide.

Results: There were 44 boys (55\%) and 36 girls (45\%), with mean age of $5.176( \pm 1.873)$ years, and the highest frequency of adenoid hypertrophy was found in the age group of 4 to 6 years $(62.45 \%)$; the most common grade of the adenoid size in all the types of the assessment was grade 3 . The assessment of adenoid grading by both flexible and peroperative rigid nasal endoscopy versus radiology was statistically significant, with $p$ value of 0.0001 , while the adenoid grading between flexible and peroperative rigid nasal endoscopic assessment was almost comparable, as no significant difference was found, with $p$ value of 0.46 .

Conclusion: Flexible nasopharyngoscopy was a more reliable diagnostic tool in the assessment of the adenoid size than lateral nasopharyngeal X-ray, as it correlates well with peroperative rigid nasal endoscopic finding.

Keywords: Adenoid hypertrophy, Nasal endoscopy, X-ray nasopharynx.

How to cite this article: Dawood MR, Khammas $A H$. Diagnostic Accuracy of Radiology and Endoscopy in the Assessment of Adenoid Hypertrophy. Int J Otorhinolaryngol Clin 2017;9(1):6-9.

\section{Source of support: Nil}

Conflict of interest: None

${ }^{1}$ Assistant Professor, ${ }^{2}$ Professor

1,2Department of Otorhinolaryngology, College of Medicine Al-Mustansiriya University, Baghdad, Iraq

Corresponding Author: Mohammed R Dawood, Assistant Professor, Department of Otorhinolaryngology, College of Medicine, Al-Mustansiriya University, Baghdad, Iraq, Phone: +009647902186858, e-mail: mohmadradef@yahoo.com

\section{INTRODUCTION}

The adenoid is a mass of lymphoid tissue embedded in the mucosal membrane of the nasopharynx. In general, it attains its maximum size between the age of 3 and 7 years and then regresses. ${ }^{1}$ The adenoid plays an important role in the immunological services of the body in growing children; however, because of various etiologies, such as upper respiratory tract infection, allergic episodes, and others, it becomes hypertrophied, and this enlargement in its size may lead to certain consequences, such as nasal obstruction, snoring and mouth breathing, sleep disturbance, Eustachian tube obstruction, otitis media, failure to thrive, and maxillofacial growth anomalies, in young children. ${ }^{2}$ Adenoid hypertrophy is a common disease in children, and its measurement had been reported by various methods, including clinical examination, imaging techniques, and endoscopy. Although these different objective diagnostic methods had been used for adenoid hypertrophy, the role of each one is still controversial, and currently there are no comprehensive and accepted guidelines by authors for adenoid size assessment. $^{3}$

As the clinical examination of children is notoriously unreliable especially in young children, a lateral radiograph of the nasopharynx can be very helpful in the assessment of the adenoid size and more important is its relation with the size of nasopharynx; however, its role in the evaluation of the adenoid hypertrophy has been less popular at the turn of the last century, with the egress of flexible fiberoptic nasopharyngoscopy, which has been regarded as a standard diagnostic modality that can give a valuable assistance for careful selection of candidates for adenoidectomy in order to avoid unnecessary operations. ${ }^{4}$

The aim of this study was to clarify the diagnostic accuracy of the lateral X-ray of nasopharynx and the flexible nasopharyngoscopy in the assessment of adenoid hypertrophy with preoperative rigid nasal endoscopic observation, as it was considered to be a reference standard.

\section{MATERIALS AND METHODS}

This was a prospective observational study conducted from May 2015 to May 2016; 80 children who planned to undergo adenoidectomy due to symptoms found related 
to the adenoid hypertrophy were enrolled in this study; the exclusion criteria included a child who was uncooperative for flexible nasopharyngoscopic examination; those with nasal pathologies other than adenoid, acute upper respiratory tract infection at the time of examination, and congenital craniofacial anomalies.

All children who participated underwent a full ear, nose, and throat (ENT) examination with particular attention to the nose, as the postrhinoscopic evaluation of size of adenoid was done by both preoperative skull lateral X-ray and flexible fiberoptic nasopharyngoscopy, as the assessment of the postnasal space by postnasal mirror was almost impractical to be performed especially in young children, and then these observations were blindly assessed by peroperative rigid nasal endoscopy of the nasopharynx under general anesthesia, as its finding was considered to be a standard reference guide for the other methods of assessment, as it measured the actual size of the adenoid tissue. Radiographs were obtained from the children in the erect position and their neck slightly extended using a Siemens Multix machine. The X-ray field was collimated to the nasopharynx, with 40 inches focus film distance, with mean exposure factors of $60 \mathrm{kV}$ and $3.2 \mathrm{mAs}$, and assessed by the institute radiologist who was blinded from the endoscopic evaluation. The assessment was performed according to Fujiokas method, ${ }^{5}$ which assessed the adenoid size and the adenoid/nasopharyngeal ratio (A/N ratio) as follows: Grade 1 was tagged as (small size) adenoid size 0.3 to 0.5 , grade 2 was tagged as (medium size) adenoid size 0.5 to 0.7 , and grade 3 was tagged as (large size) adenoid size 0.7 to 1.0.

The endoscopic examination was performed first by preoperative fiberoptic nasopharyngoscope using $2.7 \mathrm{~mm}$ type Optim $3.6 \mathrm{~mm}$, field of view $70^{\circ}$ (model 00413) device by an ENT surgeon who was blinded from radiological assessment, and the grading was classified according to Clemens et $\mathrm{al}^{6}$ classification of adenoid size as follows: Grade 1 was classified as adenoid tissue filling one-third of the vertical portion of choana, grade 2 was classified as adenoid tissue filling from one-third to two-thirds of the choana, grade 3 was classified as adenoid tissue filling from two-thirds to nearly complete obstruction, and grade 4 was classified as complete choanal obstruction. The second endoscopic examination was performed preoperatively under general anesthesia as its finding was considered as a reference guide using rigid nasoscope $0^{\circ}$ $4 \mathrm{~mm}$ (Stryker 5900), and its images were captured, which measure the actual size of the adenoid and its relation to the choana and graded according to Clemens et al classification, in the same manner as previously done with flexible endoscopy.

The study was approved by the ethical and the scientific committee of the institution, and informed consent from parents of the participating children was taken, as well as the patients' hospital registered numbers were recorded.

\section{Statistical Analysis}

Statistical Package for the Social Sciences (SPSS) (version 22) using Pearson chi-squared test for comparison between the three methods was used, considering a p-value $<0.05$ as a statistically significant value.

\section{RESULTS}

Among 80 children aged 4 to 12 years, there were 44 boys (55\%) and 36 girls (45\%), with mean age of 5.176 $( \pm 1.873)$, and the most common age group affected was 4 to 6 years $(62.45 \%)$.

The most common grade of the adenoid size detected by radiology and flexible and rigid endoscopy was grade 3 , in the frequencies of 40,40 , and $42.5 \%$ respectively.

The results of the adenoid size assessment by lateral X-ray of the nasopharynx in relation to both flexible nasopharyngoscopy and peroperative rigid nasal endoscopy revealed that out of 20 children who were graded 1 by $X$-ray, 18 and 16 of them were upgraded to grade 2 , and the remaining 2 and 4 children were upgraded to grade 3 , by flexible and peroperative rigid nasal endoscopy respectively; while out of 28 children who were graded as grade 2 by X-ray, 24 and 20 children of them were upgraded to grade 3 by flexible and peroperative rigid nasal endoscopy respectively, and in regard to 32 children with grade 3 as assessed by X-ray, only 6 and 4 children were upgraded to grade 4 by flexible and peroperative rigid nasal endoscopy respectively, as it was statically significant with $\mathrm{p}$ value of 0.0001 , as shown in Tables 1 and 2 .

The grading of adenoid size assessed by both types of endoscopy showed that out of 26 children with grade 2 assessed by flexible nasopharyngoscopy, only 2 children were upgraded to grade 3 when they were assessed by peroperative rigid nasal endoscopy, while all other gradings were comparable in both types of endoscopic observation, with nonstatistically significant $p$ value of 0.46 , as shown in Table 3.

\section{DISCUSSION}

Since the adenoid tissue is located in the posterosuperior wall of the nasopharyngeal airway, its enlargement is a common cause of upper airway obstruction in children, and it has a significant impact on their quality of life, so the assessment of its size and its grading of airway obstruction were of great importance in order to provide an indication for its surgical removal and also on postoperative surgical outcome. Among the diagnostic modalities currently available, the clinical features, radiology, and 
Table 1: The correlation of the adenoid size assessed by radiology and flexible endoscopy

\begin{tabular}{|c|c|c|c|c|c|}
\hline \multirow{2}{*}{$\begin{array}{l}\text { Adenoid } \\
\text { size by } \\
\text { lateral } \\
X \text {-ray }\end{array}$} & \multicolumn{4}{|c|}{$\begin{array}{c}\text { Adenoid grade by flexible } \\
\text { nasopharyngoscopy }\end{array}$} & \multirow[b]{2}{*}{ Total } \\
\hline & Grade 1 & Grade 2 & Grade 3 & Grade 4 & \\
\hline Grade 1 & 0 & $18(22.5 \%)$ & $2(2.5 \%)$ & 0 & $20(25 \%)$ \\
\hline Grade 2 & 0 & $4(5 \%)$ & $24(30 \%)$ & 0 & $28(35 \%)$ \\
\hline Grade 3 & 0 & $4(5 \%)$ & $22(27.5 \%)$ & $6(7.5 \%)$ & $32(40 \%)$ \\
\hline Total & 0 & $26(32.5 \%)$ & $48(60 \%)$ & $6(7.5 \%)$ & $80(100 \%)$ \\
\hline
\end{tabular}

Note: $p=0.0001$ (highly significant using Pearson chi-squared test at 0.05 level of significance)

Table 3: The measurement of the adenoid size assessed by both flexible and peroperative nasal endoscopy

\begin{tabular}{lll}
\hline Grading & $\begin{array}{l}\text { Flexible } \\
\text { nasopharyngoscopy }\end{array}$ & $\begin{array}{l}\text { Peroperative nasal } \\
\text { endoscopy }\end{array}$ \\
\hline Grade 1 & $0(0 \%)$ & $0(0 \%)$ \\
Grade 2 & $26(32.5 \%)$ & $24(30 \%)$ \\
Grade 3 & $32(40 \%)$ & $34(42.5 \%)$ \\
Grade 4 & $22(27.5 \%)$ & $22(27.5 \%)$ \\
\hline Total & $80(100 \%)$ & $80(100 \%)$ \\
\hline
\end{tabular}

Note: $p=0.46$ (not significant using Pearson chi-squared test at 0.05 level of significance)

endoscopy were still extensively used, so many researchers were in concern about finding the ideal modality for its assessment. ${ }^{\text {? }}$

In the current study, the most common age group affected were 4 to 6 years $(62.45 \%)$, and these observations were almost comparable with other studies, as Bercin et $\mathrm{al}^{8}$ reported that the maximum adenoid size detected was the age group of 3 to 7 years.

The reasons for this high incidence were probably rapid growth of the adenoid tissue, narrow nasopharynx, as well as the highest frequency of recurrent upper respiratory tract infection because of low immunity in young children, ${ }^{9}$ while Pruzansky ${ }^{10}$ reported in his study that the maximum frequency was in the age group of 6 to 8 years, and this difference in the incidence was probably due to the different culture and community lifestyle, as well as the socioeconomic status of the children enrolled in the study.

The current study found that assessment of the adenoid size by preoperative flexible nasopharyngoscopy was better than that with preoperative lateral skull $\mathrm{X}$-ray of the nasopharynx, as the p-value was 0.0001 (highly statistically significant difference between the two methods of assessment), and these findings were confirmed by almost the same observation in the grading in the size of the adenoid tissue when it was assessed with both preoperative flexible nasopharyngoscope and peroperative rigid nasal endoscope, as the $p$-value was 0.46 (no statistically significant difference between the findings with both methods of assessment). It is worth
Table 2: The correlation of the adenoid size assessed by radiology and preoperative endoscopy

\begin{tabular}{llllll}
\hline \multirow{2}{*}{$\begin{array}{l}\text { Adenoid } \\
\text { size by } \\
\text { lateral }\end{array}$} & \multicolumn{4}{c}{$\begin{array}{c}\text { Adenoid grade by peroperative } \\
\text { nasal endoscopy }\end{array}$} \\
\cline { 2 - 5 } X-ray & Grade 1 & Grade 2 & Grade 3 & Grade 4 & Total \\
\hline Grade 1 & 0 & $16(20 \%)$ & $4(5 \%)$ & $0(0 \%)$ & $20(25 \%)$ \\
Grade 2 & 0 & $8(10 \%)$ & $20(25 \%)$ & $0(0 \%)$ & $28(35 \%)$ \\
Grade 3 & 0 & $0(0 \%)$ & $28(35 \%)$ & $4(5 \%)$ & $32(40 \%)$ \\
\hline Total & 0 & $24(30 \%)$ & $52(65 \%)$ & $4(5 \%)$ & $80(100 \%)$ \\
\hline
\end{tabular}

Note: $p=0.0001$ (highly significant using Pearson chi-squared test at 0.05 level of significance)

mentioning that, the peroperative observation was considered as a reference standard guide compared with the other methods, because the peroperative endoscopy will capture the actual size of the adenoid tissue.

There were many factors that influenced X-ray to underdiagnose adenoid hypertrophy when it was compared with nasal endoscopy, such as the lack of standardization of $\mathrm{X}$-ray, the two-dimensional (2D) view by $X$-ray rather than the three-dimensional (3D) view by endoscope. ${ }^{11}$ Also, the positional changes and respiration movement, ${ }^{12}$ together with the lateral rather than the anterior direction of the growth of the adenoid enlargement, could be missed by radiology of the nasopharynx. ${ }^{13}$

These findings in the current study were confirmed by the observation of other studies, as those done by Yassen et $\mathrm{a} 1^{14}$ concluded that evaluation by endoscope was highly accurate than by $\mathrm{X}$-ray. Lourenco et $\mathrm{al}^{11}$ found in the mouth breather that children who showed small adenoid by $\mathrm{X}$-ray mostly had medium size adenoid when detected by nasoscope, and those with medium and large size adenoid by X-ray were mostly considered both large by nasoscope. Souza and Hennemann ${ }^{15}$ studied X-ray of postnasal space that showed no sign of airway obstruction, but $27 \%$ of them had severe hypertrophy of the adenoid as were detected by fiberoptic nasoscopy. These results were also supported by other studies. ${ }^{16,17}$

A study performed by Gill et $\mathrm{al}^{18}$ concluded that although the nasal endoscope is an emerging gold standard method for diagnosis of adenoid hypertrophy, as some cases were underdiagnosed by lateral X-ray as compared with nasal endoscopy, the lateral X-ray of the nasopharynx still serves as a reliable diagnostic tool, and both modalities are considered complementary to each other and serve in the best interest of the patient.

Another important fact to be considered in the favor of nasal endoscopy is that it had an important role in differentiation of adenoid tissue from other postnasal masses, which may show the same appearance on plain X-ray as tumor, granuloma, and aneurysm. ${ }^{14}$

However, nasoscopy requires the cooperation of the child and may be difficult to perform in young children, 
also it is an invasive procedure, and sometimes based on subjective analysis, especially if not incorporated with camera, so it may reveal some discrepancies, ${ }^{19}$ as well as the advantages of X-ray of nasopharynx; it is a noninvasive procedure, can be tolerated by small children who cannot tolerate nasal endoscopy, as well as it could give some assessment of the size of the adenoid tissue in relation to the size of the nasopharynx. For these reasons, it may still be used by some clinicians in various centers. ${ }^{20}$

\section{CONCLUSION}

Flexible nasopharyngoscopy is a more accurate diagnostic modality than nasopharyngeal radiology in the assessment of the adenoid grading, as it was confirmed by peroperative rigid nasal endoscopic observation, which was considered as the reference standard guide.

\section{RECOMMENDATION}

Since the flexible nasopharyngoscope was regarded as a reliable diagnostic tool for the assessment of adenoid hypertrophy, for more secure indications for adenoidectomy, and to avoid unnecessary operations, any child with symptoms of upper air obstruction suspected to be related to adenoid hypertrophy, even when there were no evidence of adenoid enlargement revealed by lateral X-ray of the nasopharynx, for an accurate assessment of the adenoid size, should be submitted to flexible nasopharyngoscopy.

\section{REFERENCES}

1. David, LC; John, H. Tonsils and adenoids. In: David, AA; Michael, JC, editors. Scott-Brown's otolaryngology. 6th ed. Vol. 6. Oxford: Butterworth Heinemann; 1997. p. 6/18/1-16.

2. Abdollahi-Fakhim S, Naderpoor M, Shahid N, Javadrashid $\mathrm{R}$, Mashrabi O, Ravaghi M. Assessment of adenoid size in children. Res J Biol Sci 2008;3(7):747-749.

3. Lertburapa K, Schroeder JW, Sullivan C. Assessment of adenoid size: a comparison of lateral radiographic measurement, radiologist assessment, and nasal endoscopy. Int J Pediatr Otorhinolaryngol 2010 Nov;47(11):1281-1285.

4. Kurien M, Lepcha A, Mathew J, Ali A, Jeyaseelan L. X-ray in the evaluation of adenoid hypertrophy: its role in endoscopic era. Indian J Otolaryngol Head Neck Surg 2005;57(1):45-47.

5. Fujioka M, Young LW, Girdany BR. Radiographic evaluation of adenoid size in children: adenoidal-nasopharyngeal ratio. AMJ radio 1979 Sep;133(3):401-404.
6. Clemens J, McMurray JS, Willging JP. Electrocautery versus curette adenoidectomy: comparison of postoperative results. Int J Pediatr Otorhinolaryngol 1998 Mar;43(2):115-122.

7. Jeans WD, Fernando DCJ, Maw AR. How should adenoidal enlargement be measured? A radiological study based on inter observer agreement. Clin Radio 1981 May;32(3): 337-340.

8. Bercin AS, Ural A, Kutluhan A, Yurttas V. Relationship between sinusitis and adenoid size in paediatric age group. Ann Otol Rhinol Laryngol 2007 Jul;116(7):550-553.

9. Lusk RP, Stankiewicz JA. Paediatric rhinosinusitis: report of the rhinosinusitis. Task Force Committee Meeting. Otolaryngol Head Neck Surg 1997 Sep;117(Suppl):S53-S57.

10. Pruzansky S. Roentgen cephalometric studies of tonsil and adenoid in normal and pathological states. Ann Otol Rhinol Laryngol 1975 Mar;84:55-62.

11. Lourenco EA, Lopes Kde C, Pontes A Jr, Oliveira MH, Umemura A, Vargas AL. Comparison between radiological and nasopharyngolaryngoscopic assessments of adenoid tissue volume in mouth breathing children. Rev Bras Otorhinolaryngol 2005 Feb;71(1):23-27.

12. Britton PD. Effect of respiration on nasopharyngeal radiographs when assessing adenoidal enlargement. J Laryngol Otol 1989 Jan;103(1):71-73.

13. Wright Ed, Pearl AJ, Manoukian JJ. Laterally hypertrophic adenoid as contributory factor in otitis media. Int J Ped Otolaryngol 1998 Oct;45(3):207-214.

14. Yassen ET, Khammas AH, Anbaky F. Adenoid enlargement assessment by plain $\mathrm{x}$-ray and nasoendoscopy. Iraqi J Comm Med 2012;1:88-91.

15. Souza BB, Hennemann GV, Anselmo-Lima WT. Importance of nasal fiberoptic examination in the presence of a normal x-ray of the cavum. Int J Pediatr Otolaryngol 2000 Sep;55(1): 29-32.

16. Yilmas I, Cay F, Lacks, Yilmazer C, Sener M, Ozluoglug. Correlation of diagnostic system with adenoid tissue volume: a blind prospective study. Int J Ped Otolaryngol 2008 Aug;72(8):1235-1240.

17. Kindermann CA, Roithmann R, Lubianconeto JF. Sensitivity and specificity of nasal flexible fiberoptic endoscope in diagnosis of adenoid hypertrophy in children. Int J Ped Otolaryngol 2008 Jan; 72(1):63-67.

18. Gill JS, Bhardwaj B, Anand V, Singla S. The comparative roles of $\mathrm{x}$-ray nasopharynx and nasal endoscopy in diagnosis of adenoid hypertrophy. Nepalese J ENT Head Neck 2013;4(1):26-28.

19. Calylaki F, Hizal E, Yilmaz I, Yilmazer C. Correlation between adenoid-nasopharynx ratio and endoscopic examination of adenoid hypertrophy: a blind prospective clinical study. Int J Pediatr Otolaryngol 2009 Nov;73(11):1532-1535.

20. Hibbert J, Whitehouse GH. The assessment of adenoid size by radiological means. Clin Otolaryngol 1978 Feb;3(1):43-47. 